\title{
Intelligent building maintenance - A novel discipline
}

Received (in revised form): 28th March, 2008

\section{Chung Yim Yiu}

is currently an assistant professor in the Department of Real Estate and Construction, the University of Hong Kong. He is a qualified building surveyor, and a corporate member of the Royal Institute of Chartered Surveyors, and the Hong Kong Institute of Surveyors. His research interests and expertise are in building maintenance, property and construction economics, and finance.

Correspondence: Chung Yim Yiu, Department of Real Estate and Construction, The University of Hong Kong, Pokfulam, Hong Kong, China; Tel: +852 2857 8629; Fax: +852 2559 9457; E-mail: ecyyiu@hkucc.hku.hk

\begin{abstract}
Intelligent building has been developing for more than 25 years, and has undergone four major generations. It has now been widely and deeply developed in new buildings. There is, however, no commensurate development of intelligence in building maintenance. This paper discusses the current primitive approaches in building maintenance and puts forward a novel idea of intelligent building maintenance. A learning model for building maintenance intelligence is discussed. The research agenda with some examples of this novel discipline is raised. Although intelligent building maintenance may be a fantasy today, it could bring far-reaching benefits to the health and safety of building users. Journal of Building Appraisal (2008) 3, 305-317. doi:10.1057/jba.2008.9
\end{abstract}

\section{Keywords:}

building maintenance, intelligence, learning model

\section{INTRODUCTION}

Having a dream is the impetus to new inventions. Just like the dream of having intelligent buildings in the 1980s, a New York Times article, on 13th May, 1984, described a new type of building that could think for itself. Then in November 1985, an issue of Engineering Digest published an article on building intelligence; the idea of intelligent building has become widespread and deep-rooted and is now becoming a necessary installation in all new developments.

The United Technology Building Systems Corporation advertised that the City Place Building in Hartford, Connecticut, USA completed in July 1983 was the first intelligent building; it only provided some automation in the facilities. In fact, it took several decades to make the dream come true (So et al., 1999). Building intelligence models can now be divided briefly into four main generations, namely (1) automated building, (2) responsive building,(3) effective building models (Harrison et al., 1998), and (4) learning model (Yiu and Yau, 2006), as shown in Figure 1.

The first generation of building intelligence emphasised the achievement of building automation. The second generation strengthened the responsiveness of the systems to environmental changes, such as the Variable-Air-Volume (VAV) air-conditioning system or the angle adjustment of the shading devices by sensing the direction of sunlight. Communication and integration systems have been developed to enhance the responsiveness. In the late 1990s, the idea of intelligent building was shifted from building responsiveness to the enhancement of building users' efficiency. For example, 


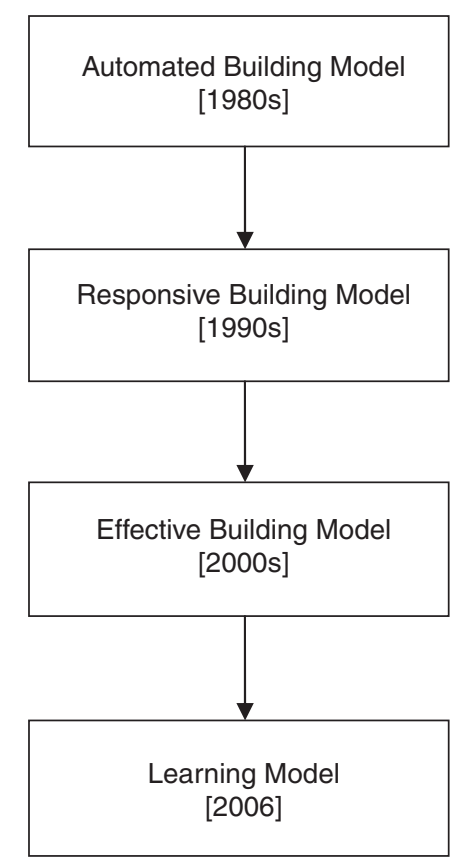

Figure I: The four generations of building intelligence

So et al. (1999) claimed that 'Intelligent buildings are not intelligent by themselves but they can furnish the occupants with more intelligence and enable them to work more efficiently'. Unfortunately, this idea has become just a slogan as it cannot be directly observed, let alone be scientifically measured. Then Yiu and Yau (2005) put forward a novel learning model of building intelligence. They argued the importance of the learning skills of a building, which entitle it to be regarded as intelligent. The first three concepts of intelligent building have been widely applied (as reviewed in Yiu and Yau, 2005), including building services installations, construction methods, environmental friendliness in the built environment, etc. The learning model, however, has just been launched, and the only example is the latest development of intelligent lifts.

Unfortunately, all intelligent building models are applied on new developments only, and there has been little discussion on any forms of intelligence on building maintenance, which is one of the major sectors of the building industry. For example, the definition of intelligent building put forward by AIIB (2001) is composed of ten quality environment modules, namely (1) environmental friendliness, (2) space utilisation and flexibility, (3) human comfort, (4) working efficiency, (5) culture, (6) image of high-technology, (7) safety and security measures, (8) construction process and structure, (9) costeffectiveness, and (10) health and hygiene, which are subdivided into hundreds of items, but very few of them are related to building maintenance. Among those maintenancerelated items, their assessments are of little intelligence; for instance, item 7.5, addressing tile debonding, refers to manual methods and thermal imaging for the identification of tile debonds. The accuracy of these two methods is well recognised to be very dependent on the experience of the operators. Similarly, item 8.11 on water leakage, recommends assessing the number of leakage points as a measure of the intelligence of the building, which is untenable. These are merely traditional condition survey items and there is no suggestion on how to identify and rectify the defects by any intelligent devices. 


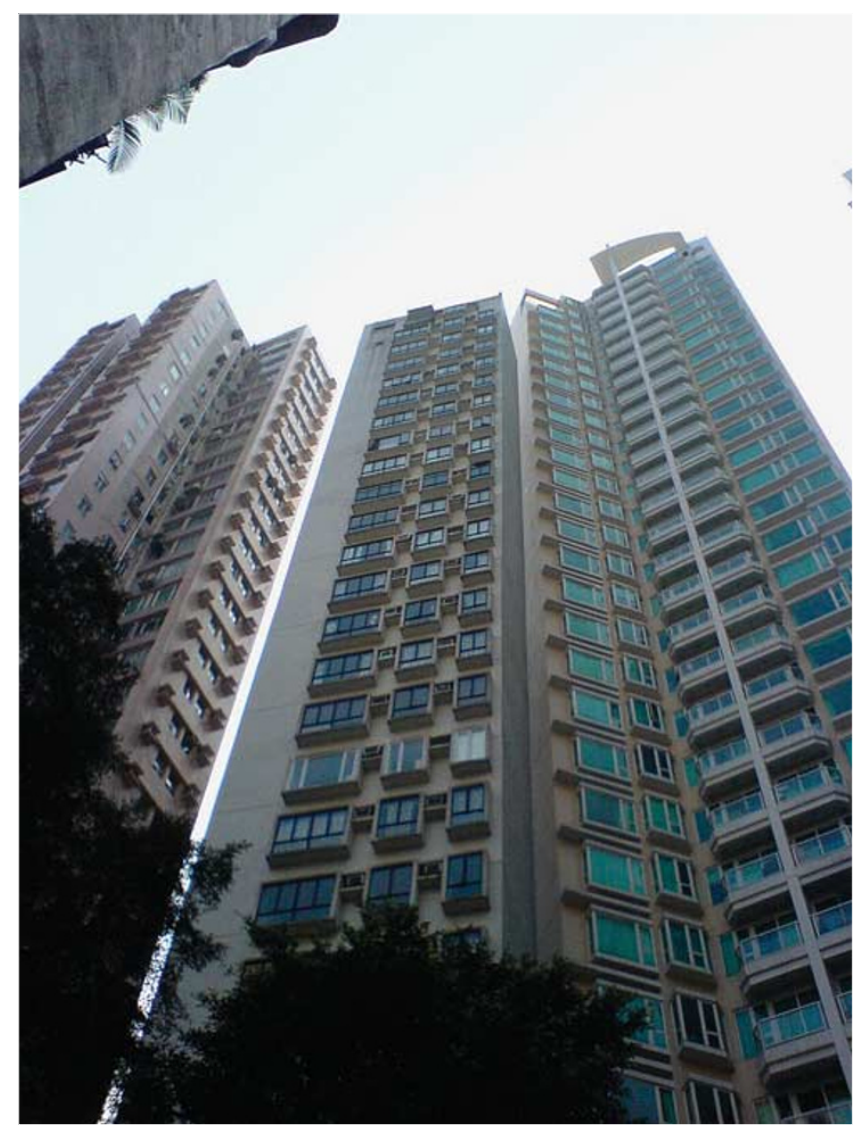

Figure 2: Skyline among buildings in Hong Kong

Unlike new developments of buildings, technologies of building maintenance are still very low-tech and labour-intensive. Inspections and diagnoses are largely based on visual methods, some Non-Destructive Tests are developing for building inspection purpose, but most of them are still of very poor predictive power. Worse still, many inspections are only carried out when symptoms have been seriously developed, because the mechanisms of building defect development are largely unseen and unknown. Building maintenance intelligence is of particular importance in the context of high-rise high-density developments in Hong Kong (Figure 2).

This paper can be regarded as an extension of the dream of intelligent building; it puts forward a novel idea of developing intelligence onto building maintenance. It is based on the Learning Model of building intelligence. Some laboratory studies on this line of thought are discussed, although they are far from materialisation.

\section{What is intelligence?}

In the first three generations of building intelligence, facilities are programmed by hardwired commands or instructions to achieve the objectives of automation, responsiveness and effectiveness, but Roger Penrose (2005), a mathematical physicist, strongly contends that such a hard-wired algorithm cannot achieve any intelligence at all. He described it as a top-down algorithm that is constructed according to some well-defined and clearly understood fixed computational procedure. This procedure specifically provides a clearcut solution to the problem at hand. 
Unfortunately, when such a hard-wired algorithm is still not available, no top-down programme can be constructed (Penrose, 2005). The Learning Model, by contrast, proposes a bottom-up (learning) approach for an intelligent building.

Contrary to the top-down approach, a learning algorithm does not specify the rules of operation in advance, "but instead there is a procedure laid down for the way that the system is to "learn" and to improve its performance according to its "experience"" (Penrose, 2005, p.18). In other words, it stresses the importance of the learning capability of an intelligent system.

Similarly, Steven Pinker (1997, p. 62), a cognitive scientist, defines intelligence as 'the ability to attain goals in the face of obstacles by means of decisions based on rational rules'. It implies learning or an adaptive mechanism in any intelligent entity, as the purpose of learning is to 'make rational prediction so as to overcome obstacles' (Johnson, 2004, p. 150). Steve Grand, a computer scientist, made it even clearer that 'the lack of learning ability disqualifies them [the top-down approach] from being described as intelligent' (Grand, 2000, p. 136). Vertosick (2002, p. 9)also claimed that 'learning is central to all intelligent behaviour'. The following definitions of intelligence also explicitly spell out the importance of learning and adaptation capability:

\footnotetext{
'Intelligence is an ability to adapt effectively to the environment, either by making a change in oneself or by changing the environment or finding a new one'. (Encyclopaedia Britannica, 1986)

'Intelligence is a general mental capability that involves the ability to reason, plan, solve problems, think abstractly, comprehend ideas and language, and learn'. (Wikipedia, 2005)

'Intelligence is a very general mental capability that, among other things, involves the ability to reason, plan, solve problems, think abstractly, comprehend complex ideas, learn quickly and learn from experience'.(Wall Street Journal, 1994)
}

This learning approach, which relies on the learning capability of the system, provides a truly intelligent way to solve problems. With a learning algorithm, the system is allowed to experience, adapt, feedback, and learn. On each trial, an assessment is made and the rules of decisions are modified, with a view to improving the chance of attaining the goals. This learning process improves its performance or predictive power by 'experience'.

Such a learning model is more appropriate for the development of building maintenance intelligence, because the 'instructions' in the top-down algorithm do not exist.

\section{The learning model of building intelligence}

What makes an intelligent building differentiable from an un-intelligent one is its ability to adapt to dynamic environmental changes by a learning algorithm so as to attain the goals in a self-organising manner, without relying on external commands. Thus, building intelligence shall include a self-improving (learning) mechanism, which shall (1) make response to new change; (2) feedback and monitor the performance of such a change; (3) record down the response and performance in a memory; (4) control or adjust the response to achieve a better performance; (5) compare with the previous performance to learn which response is better; and finally (6) designate the best responses for future changes. These form the six major sub-systems of intelligence, namely, (1) control; (2) memory; (3) learning; (4) feedback and monitoring; (5) automatic response; and (6) choice of alternative responses, as shown in Figure 3.

These six sub-systems form the core of the learning model of building intelligence. In an ever-changing environment, the learning system must be adaptive (Kroner, 1997; 


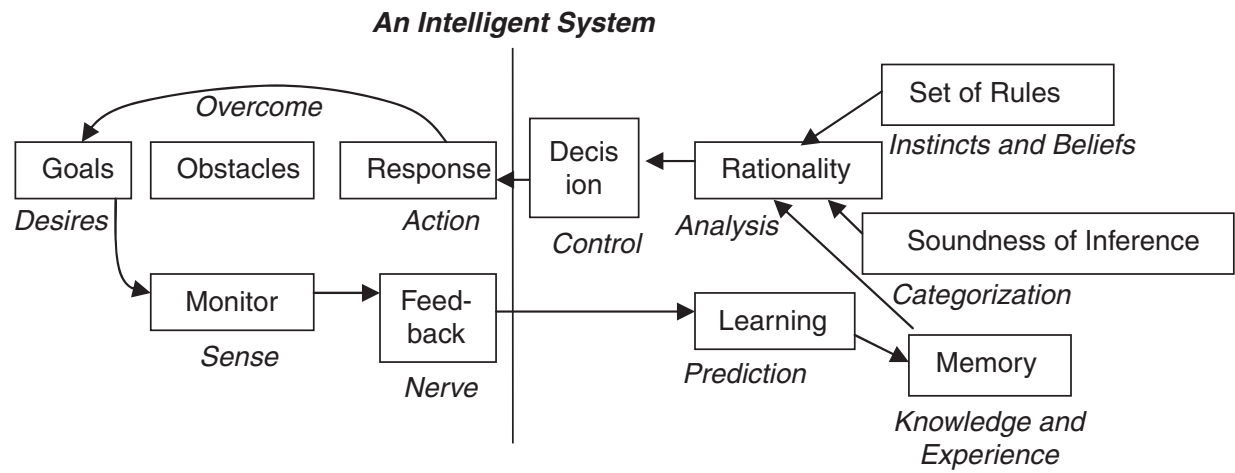

Figure 3: The learning model of building intelligence

Mozer, 1999). In the case of building defects, because the current knowledge does not enable programmers to diagnose and rectify the defects correctly, the systems have to continuously recognise, learn and adapt to the changing activities and user requirements of the inhabitants (Clements-Croome, 1997).

As recognition involves comparisons, the systems must be equipped with a gigantic memory system for experience (and knowledge) storage for comparison. The learning system refers to an analytical or a trial and error algorithm, which allows the systems to learn from previous information and mistakes for understanding the causes and effects and making predictions (Grand, 2000, p. 113), so as to increase the chance of achieving the goals. The learned knowledge will be categorised and the memory for future decisionmaking will be updated.

This learning model of building intelligence is not without shortcomings. It takes time to learn and adapt. Just like a human infant, it makes a lot of mistakes before it can stand on its own feet. It requires parental care before it grows up (technically, it means that training is required). But it is very suitable for building maintenance, because the discipline is still at its infancy.

\section{Building maintenance}

British Standards (BS 4778-3.1: 1991) defines 'maintenance as the process of maintaining an item in an operational state by either preventing a transition to a failed state or by restoring it to an operational state following failure'. Seeley (1992, p.11) posited that the purposes of building maintenance are to (1) protect the health and safety of occupants and the public at large; (2) retain value of investment; (3) maintain the building in a condition in which it continues to fulfil its functions; and (4) present a good appearance. Harris (2001) made a very good analogy between medical pathology and building pathology, as shown in Figure 4. There are various mechanisms (diseases) affecting building health and safety, but currently we know very little about them. For example, the causes of tile debonding are almost unknown scientifically, and researchers (Lo et al., 2005; Yiu et al., 2007) have just started to analyse possible causes in the laboratory.

Without understanding the mechanisms behind, the symptoms developed are directly taken as the problems to be tackled (intervened). For example, concrete spallings are often simply diagnosed as the result of expanded reinforcement bars, without realising that the loss of protection function of the concrete cover is the real cause. Patch repairs 


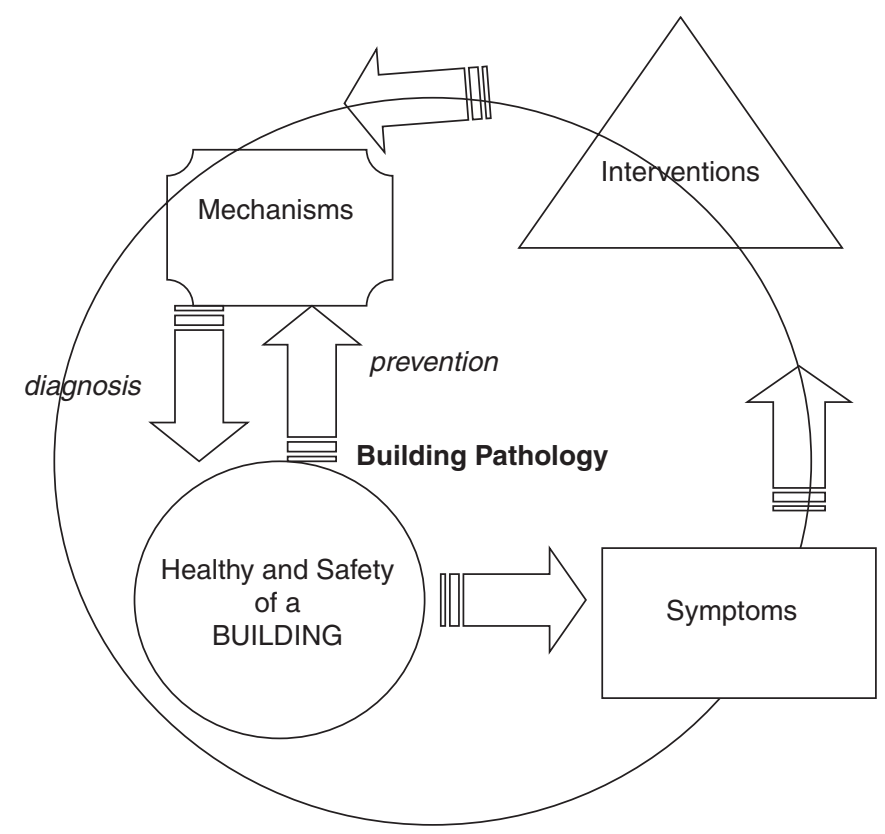

Figure 4: The Harris (200I) analogy of building pathology

are commonly applied to the spallings without diagnosis. It can sometimes be a very wrong prescription to the 'disease'. It resembles a husband-and-wife quarrel: at the time of marriage, concrete knows very well about the risk of corrosion and expansion of reinforcement bar, if she is not well protected. That is why concrete promised to protect her and to keep her away from contaminants. After several years, one day when she is sick (expands), which results in concrete spalling, she is blamed. Every couple knows that trying to remedy a relationship based on a wrong cause may do more harm than good.

Fortunately, the European Standards for Concrete Repair (EN 1504), the first international standards on concrete repair, were finally released in $2005 .{ }^{1}$ It has taken more than ten years of intensive research before it was made available. It emphasises the importance of diagnosis and the formulation of repair strategies, and it attributes concrete spalling to the loss of protection. The mechanisms causing the defects, however, are still badly understood, and the recommended interventions are limited to traditional methods.

In Harris's (2001, p. 39) terminology, there are five intervention strategies on repair, namely:

- Abstention

- Mitigation

- Reconstitution

- Circumvention

- Acceleration

Harris (2001) explained the five interventions by means of the following (negative) entropy-time curves. Figure 5 shows the natural decay curve of (negative) entropy of building systems over time when no intervention is applied, that is, abstention.

Figure 6 shows the other four intervention strategies. Mitigation is the alteration of the environment that supports the deterioration mechanism, thus reducing the rate of 


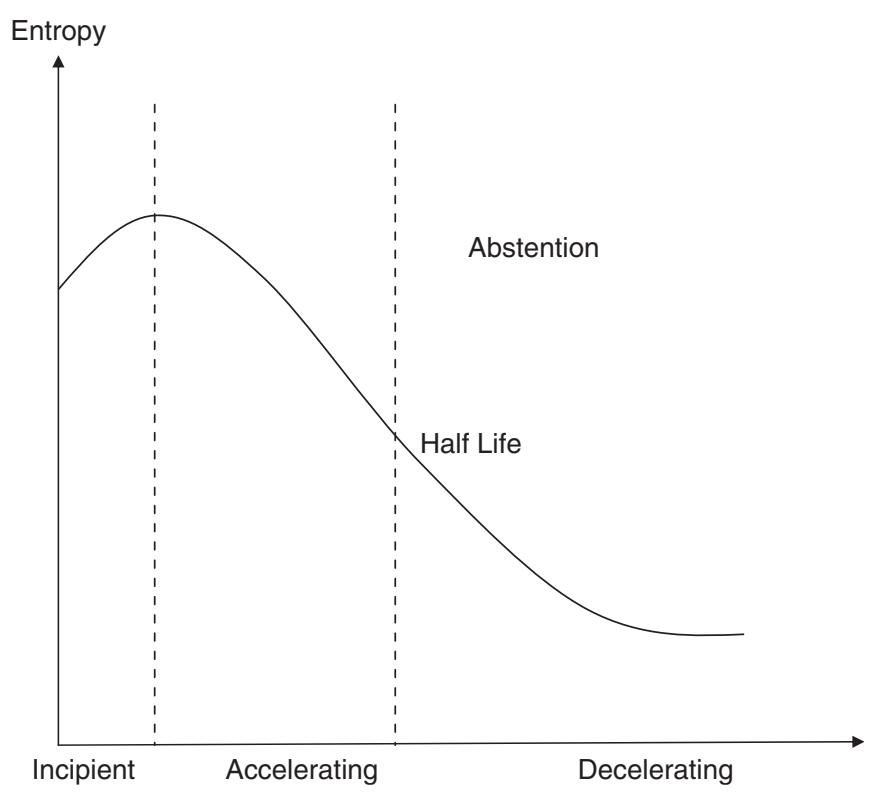

Figure 5: Building deterioration in terms of (negative) entropy-time curve (Harris, 200I)

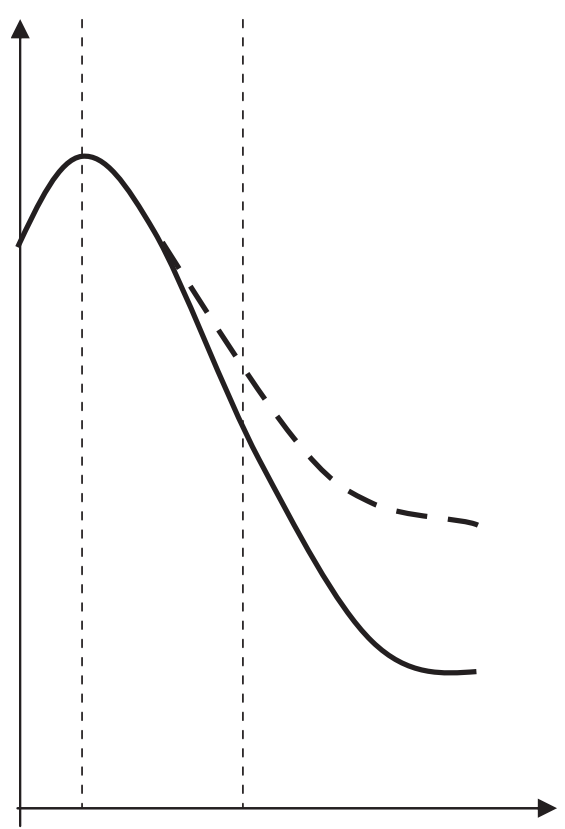

Mitigation: alter the

environment that support

the deterioration

mechanism

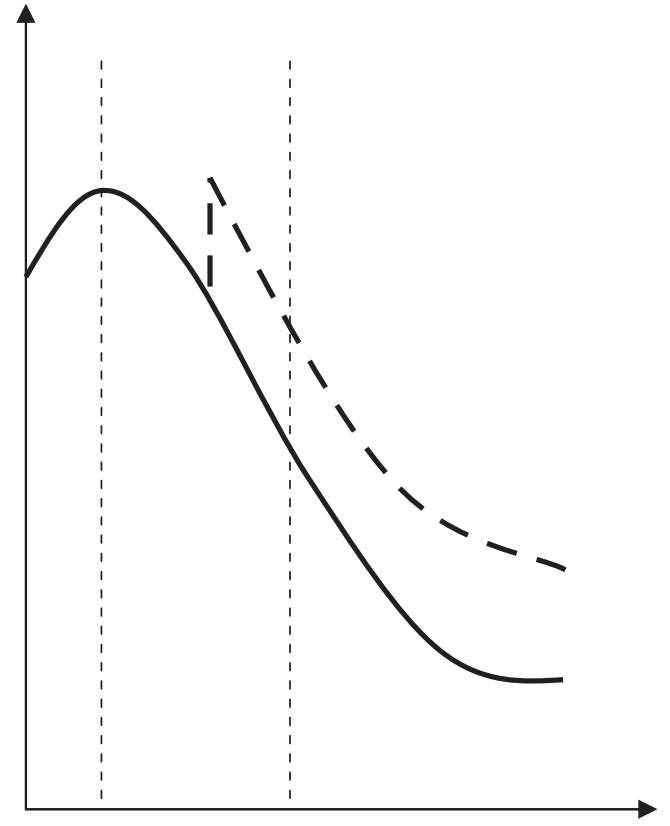

Reconstitution: alter the fabric that was deteriorating

Figure 6: Interventions to building deterioration in terms of (negative) entropy-time curve (Harris, 200I) 
(negative) entropy decay. Reconstitution refers to the alteration of the fabric that was deteriorating, thus resulting in an upward spike in (negative) entropy. Circumvention is an intervention by substituting the defective materials with other materials and functions. The rate of decay is therefore changed. Lastly, acceleration is to speed up the rate of deterioration.

These analyses of repair strategies or interventions are interesting though they do not consider any intelligence in maintenance. All are simply decision-making principles based on human judgments. But even practitioners do not always learn from such experience, as there is no feedback loop on the appropriateness of any interventions adopted. In fact, the common 'repairs on repairs' phenomenon in building defects is a very typical consequence of such a 'non-intelligent' way of decision making.

\section{Intelligence in building maintenance}

Admittedly, developing building maintenance intelligence is a bold attempt, and perhaps it may be just a dream. The idea of intelligent maintenance comes from the immune system of living organisms. Although we sometimes need to consult medical doctors and take medicines, our immune system is very effective in protecting our health. How fatal it would become when our immune system fails to perform can be perceived by the high fatality rate of patients infected with acquired immune deficiency syndrome (AIDS).

Intelligent living organisms develop a clever system of immunology to survive, which embeds all the six sub-systems of the learning model above. Viruses and bacteria are recognised by leucocytes carrying a huge memory in genes, which is updating every second in every living organism. They developed different poisons to kill any new pathogens by trials and errors. They update their library after each battle (Playfair (2004) discussed how phagocytes and lymphocytes recognise and deliver lethal hit to virus by our immune system; Vertosick (2002) addressed how the immune system feedback and learn).

Intelligence in building maintenance can be regarded as a new approach to maintain a building, which has never been explored. Other commonly adopted approaches would be to avoid any defects in the first place, for example, by keeping away from contaminants, protecting against any damage, etc or to remove any defects through various kinds of interventions. These two strategies are very commonly practiced nowadays. Yet, the two scientists, David Bohm and David Peat (2000) contended that 'the immune system is [the only approach that is] able to clear up misinformation in a natural way'.

The (negative) entropy-time curve of this immunisation system is depicted in Figure 7. Its intelligence enables the system to be self-rectifying by learning the mode of deterioration, thus resulting in several spikes of recovery of (negative) entropy.

\section{Research agenda on building maintenance intelligence}

We are still very far from achieving any significant developments in building maintenance intelligence. This paper is one of the few advocates on this idea. The following are some components of a possible research agenda, some of which are at their embryonic form in laboratory study; some may be just a fantasy at this stage.

One suggestion is a 'pain system', which continuously monitors stresses on the building and detects any abnormal stresses. In a tile debonding study, the continuous monitoring of the adhesive strength of the wall tiling system can help detect early signals of tile debonds. It can be regarded as intertwining a nerve system into the tiling system, to 


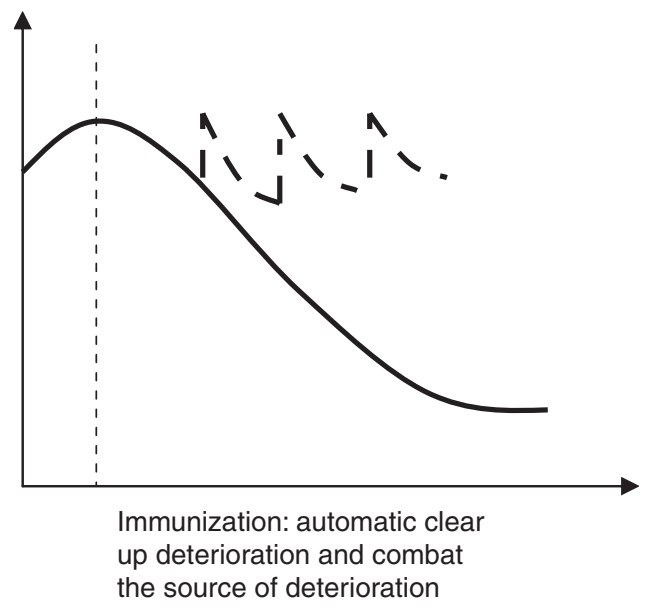

Figure 7: Immunisation to building defects in terms of (negative) entropy-time curve

continuously scrutinise the conditions of the tiling system. Laboratory studies (Lo et al., 2005; Yiu et al., 2007) have been conducted by embedding strain gauges into different layers of the tiling system. Figures 8 and 9 show the responses of the strain gauges to static and cyclic loads, respectively. The strain gauges work like our nervous system by converting the external environment changes, such as temperature and pressure on the tiling system, to a strain magnitude. The records of these strain measurements provide a very important feedback to the control that is the strongest hit on the tiling system.

Unlike pull-off tests, which are currently used to test the adhesive strength of tiling system, this method is (1) continuous rather than discrete; (2) showing the strength of individual layers rather than the aggregate; (3) non-destructive; and (4) memorising all the changes in strength over time. These are essential requirements in building an intelligent system. If the data can be fed into a learning system that can rectify the defects detected, it becomes an intelligent maintenance system.

Concrete repair is another area under study. The diffusion of contaminants and carbonation are the two major causes of damaging the protection function of the concrete cover (ENV1504, Part 9). Realkalisation and cathodic protection are now available, but are still at their infancy in terms of intelligence. For example, in the sacrificial anode system (Fosroc, 2006), the steel reinforcement bar is connected to a metal, which is less stable in electro-chemical series, such as zinc. As zinc is more anodic than steel, the current will flow from zinc to steel and zinc will be corroded instead of steel. Yet, the connection between metals is now fixed in position. If a stream of zinc ions can be circulated through the reinforcement bars to exchange for the oxides, it works like our blood flow and liver system.

There are many other potential areas to be explored. For example, waterproofing systems, especially on the rooftop, are very expensive but fragile. A small crack may require a complete replacement of the waterproofing membrane. Inspections are very difficult to be carried out as the membrane has been covered up. From an intelligent maintenance perspective, however, it can easily be tackled by embedding a detection and rectification system into the waterproofing system at the time of installation. It works very similarly to the immune system by recognising any intrusion of water, informing the control system, releasing a smart material, which grows into a fibre network and stops any further attack of water. Does that sound like blood clotting (coagulation)? That is how our body deals with damage intelligently. 
a

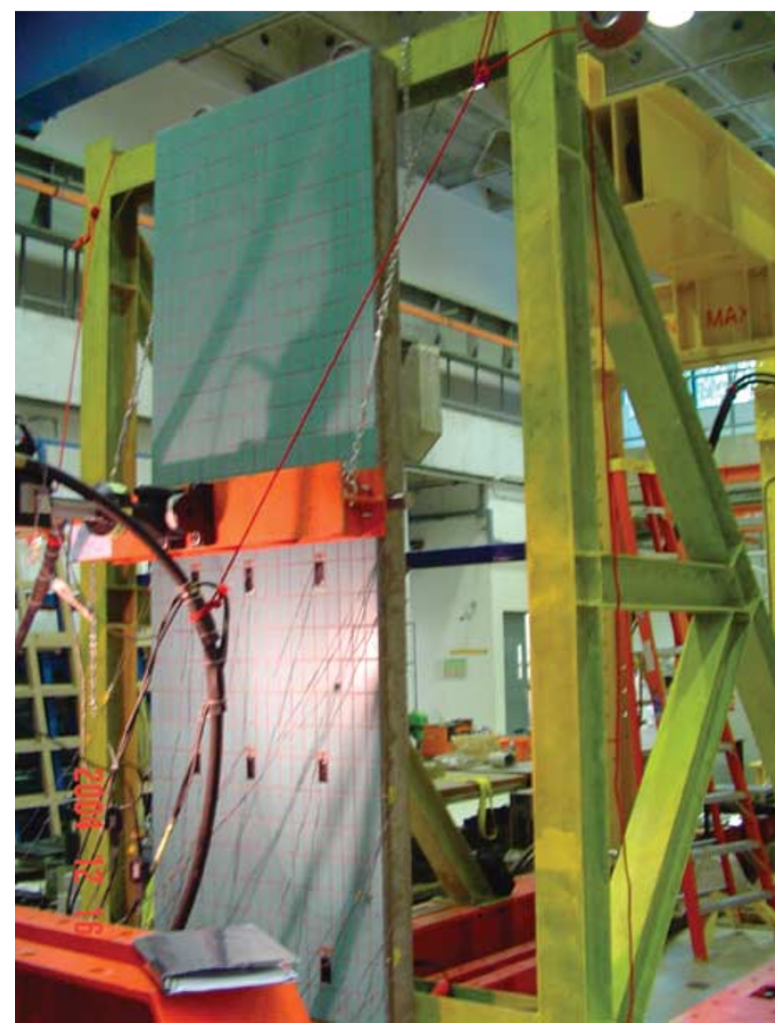

b Graph of Strain Gauge Reading against Applied Load on Concrete Surface (No.4 - No.6)

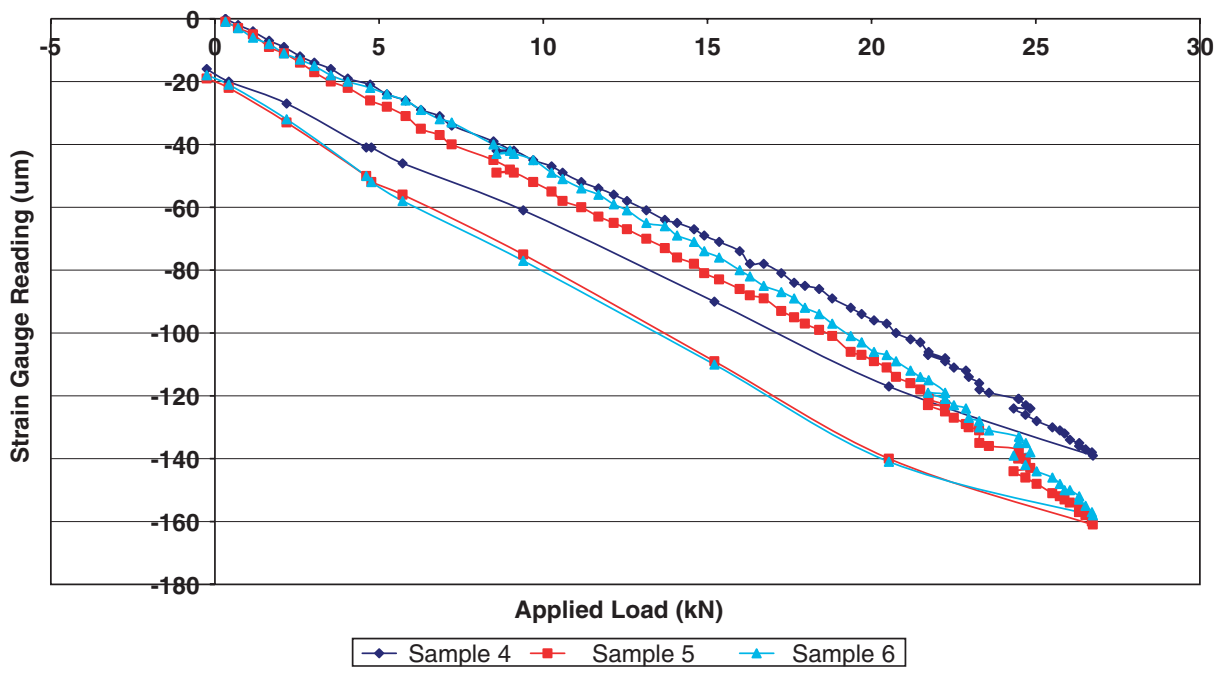

Figure 8: (a) Laboratory setup for the static load test on the wall-tiling system. (b) Results of the static load test

\section{Conclusions}

In this paper, four generations of building intelligence have been reviewed. The first three generations are more or less characterised by their emphases on communication and information technology, integration of facilities, and automation and control. They are based on hard-wired (top-down) algorithms, which have to be programmed externally to 
a
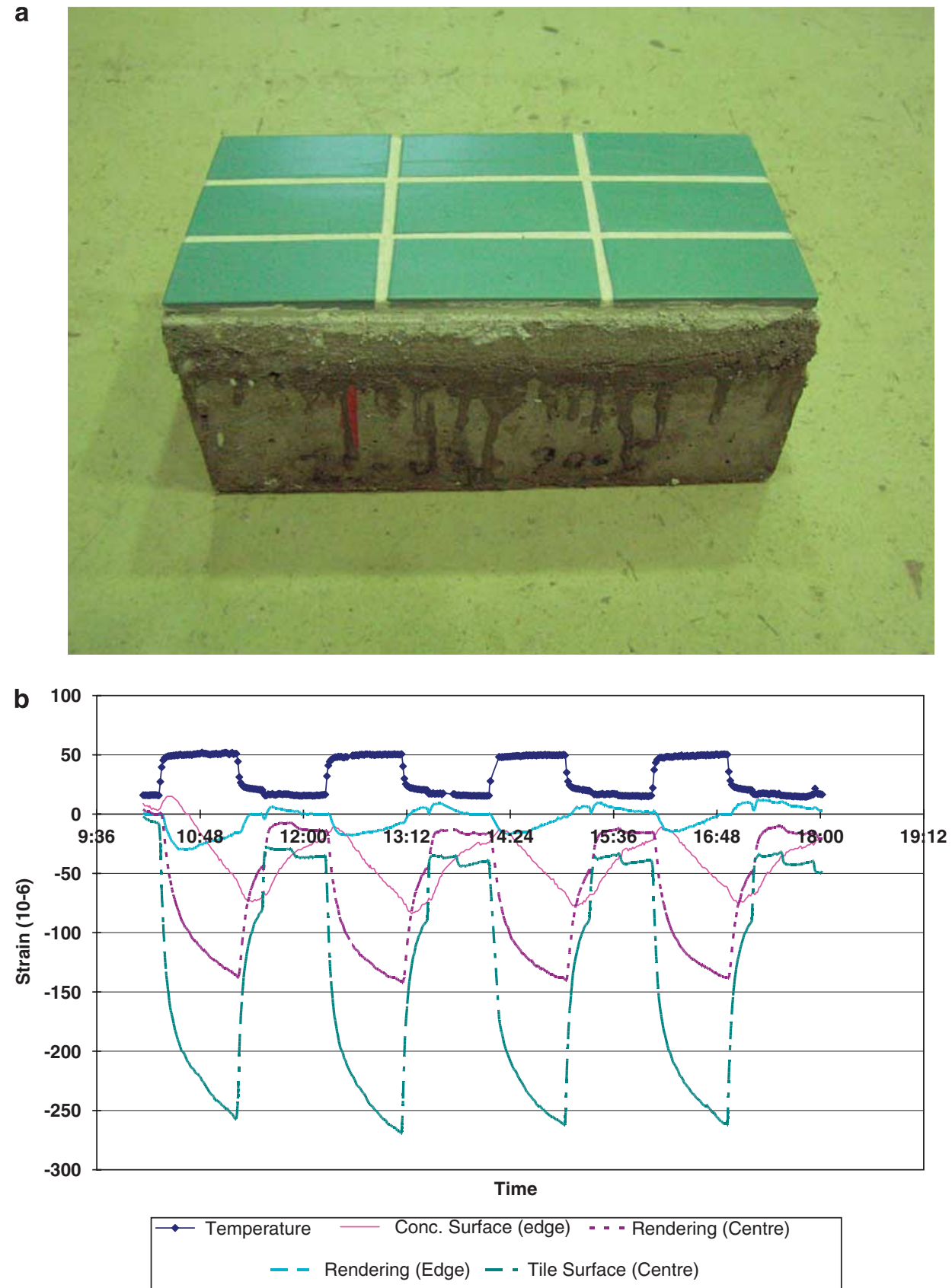

Figure 9: (a) Sample for cyclic load test on the wall-tiling system. (b) Results of the cyclic load test

make 'intelligent' decisions. Such hard-wired algorithms, however, cannot be applied when the knowledge to programme is not available. The novel learning (bottom-up) model of intelligent buildings, which emphasises learning and adaptive mechanism, contends that a learning algorithm is the necessary condition for evolving intelligence, although it takes time for the building or system to learn. This learning model provides a generic definition of building intelligence, which is conducive to the development of intelligence for building maintenance. 
Building maintenance is frequently or generally a primitive discipline in terms of its diagnosis and rectification methods. Currently, prevention of defects and removal of defects (and mainly the latter) are the major approaches in building maintenance. This paper puts forward a novel approach by introducing intelligence into the maintenance system. Analogously, it performs like our immune system in recognising and attacking foreign pathogens. Some examples, such as the monitoring of the adhesive strength in a tiling system, cathodic protection system in concrete repair and rooftop waterproofing systems, are discussed in this paper. Yet, they are still far from universal application; it will still require effort and resources to make the dream come true.

Further extending the fantasy, intelligent building systems and intelligent maintenance systems may work together one day. Just like our body, there is evidence that the 'intelligence' of the immune system can respond to higher levels of intelligence of thought and feeling. It is believed (Cousins, 1981) that optimistic thought is conducive to the immune system, with the result that a person becomes less susceptible to infections. Indeed a strong 'will to live' is crucial to general health and even to recovery from illnesses (Cousins, 1981). Would, one day, a building survive a productive life by a sheer 'will to live'? This may set out our further study in building maintenance intelligence.

\section{Note}

1 Part 9 is still in draft form at the end of 2007; its code is therefore ENV 1504-9.

\section{References}

AIIB (2001) The Intelligent Building Index Manual 2.0, Asian Institute of Intelligent Buildings, Hong Kong.

Bohm, D. and Peat, D. (2000) Science, Order and Creativity: An Investigation of Creativity in Nature and Life, Routledge, UK.

BSI (1991 BS4778-3.1: 1991) Quality Vocabulary: Part 3: Availability, Reliability and Maintainability Terms, Section 3.1 Guide to Concepts and Related Definitions, British Standards Institution, UK.

Clements-Croome, T.D.J. (1997) 'What do we mean by intelligent buildings', Automation in Construction, 6(5/6), 395400 .

Cousins, N. (1981) Anatomy of an Illness, Bantam, NY.

EN (1997 ENV 1504 — Part 9: 1997) General Principles for the Use of Products and Systems, July 1997 European Standards.

EN (1999-2005 EN 1504) European Standards for Concrete Repair European Standards.

Encyclopaedia Britannica (1986) The New Encyclopaedia Britannica, Encyclopaedia Britannica, London.

Fosroc (2006) Galvashield XP, http://www.studiolina.com/studio/websites/fosroc, retrieved in August 2006.

Grand, S. (2000) Creation: Life and How to Make It, Harvard University Press, MA, US.

Harris, S.Y. (2001) Building Pathology: Deterioration, Diagnostics, and Intervention, John Wiley \& Sons, Inc., NY. Harrison, A., Loe, E. and Read, J. (1998) (eds) Intelligent Buildings in South East Asia, E \& FN Spon, London. Johnson, S. (2004) Mind Wide Open: Why You Are What You Think, Penguin Books, London.

Kroner, W.M. (1997) 'An intelligent and responsive architecture', Automation in Construction, 6, $381-393$.

Lo, S.M., Ho, C.W., Yiu, C.Y., Yang, D.Q. and Man, S.K. (2005) 'A study on the debonding of external wall tiles for high-rise buildings in Hong Kong', in Cheung, Y.K. and Chau, K.W. (eds) Tall Buildings: From Engineering to Sustainability, World Scientific, New Jersey, pp. 700-706.

Mozer, M.C. (1999) 'An intelligent environment must be adaptive', IEEE Intelligent Systems and their Applications, $14(2), 11-13$.

Penrose, R. (2005) Shadows of the Mind: A Search for the Missing Science of Consciousness, Vintage, London.

Pinker, S. (1997) How the Mind Works, Penguin Books, London.

Playfair, J. (2004) Living with Germs in Sickness and in Health, Oxford University Press, UK.

Seeley, I.H. (1992) Building Maintenance, 2nd edn, Macmillan, Basingstoke, UK.

So, A.T.P., Wong, A.C.W. and Wong, K.C. (1999) 'A definition of intelligent buildings for Asia', Facilities, 17(12/13), $485-491$. 
Vertosick Jr., F.T. (2002) The Genius Within: Discovering the Intelligence of Every Living Thing, Harcourt, NY. Wall Street Journal (1994) 'Intelligent building', Wall Street Journal, 13th December, p. A18.

Wikipedia (2005) 'Intelligence', The Free Encyclopaedia, available at http://en.wikipedia.org/wiki/Intelligence, accessed on 14th December, 2005.

Yiu, C.Y., Ho, C.W. and Lo, S.M. (2007) 'Weathering effects on external wall tiling systems', Construction and Building Materials, 21(3), 594-600.

Yiu, C.Y. and Yau, Y. (2006) 'A learning model of intelligent home', Facilities, 24(9/10), 365-375. 